\title{
Cross-protection studies between respiratory and calf diarrhea and winter dysentery coronavirus strains in calves and RT-PCR and nested PCR for their detection
}

\author{
K.-O. Cho*, M. Hasoksuz ${ }^{* *}$, P. R. Nielsen, K.-O. Chang, \\ S. Lathrop***, and L. J. Saif \\ Food Animal Health Research Program, Department of Veterinary Preventive Medicine, \\ Ohio Agricultural Research and Development Center, The Ohio State University, \\ Wooster, Ohio, U.S.A.
}

Accepted January 17, 2001

Summary. A 1-step RT-PCR assay, targeting a $730 \mathrm{bp}$ fragment of the nucleocapsid (N) gene of bovine coronavirus (BCV), and a nested PCR assay, targeting a 407 bp fragment of the $\mathrm{N}$ gene, were developed to detect BCV in nasal swab and fecal samples of calves experimentally exposed to BCV. Both 1-step RT-PCR and nested PCR recognized cell culture passaged isolates of 10 bovine respiratory coronavirus (BRCV), 5 calf diarrhea (CD) and 8 winter dysentery (WD) strains of $\mathrm{BCV}$, but not transmissible gastroenteritis coronavirus or bovine rotavirus. The sensitivity of the 1-step RT-PCR and nested PCR was compared to that of an antigen-capture ELISA. The lowest detection limit of the 1-step RT-PCR and nested PCR as determined by using tenfold serial dilutions of the BRCV 255 and 440 strains in BCV negative nasal swab suspensions from preexposure gnotobiotic calves was $2 \times 10^{4}$ and $2 \times 10^{2} \mathrm{TCID}_{50} / 0.1 \mathrm{ml}$ for each strain, respectively. The lowest detection limit of the antigen-capture ELISA as determined by using the same serially diluted samples was $1 \times 10^{6} \mathrm{TCID}_{50} / 0.1 \mathrm{ml}$ for each strain. Therefore, the 1-step RT-PCR and nested PCR assays were 50 and 5000 times, respectively more sensitive than the antigen-capture ELISA to detect BRCV in nasal swab suspensions. To investigate in vivo cross-protection between the BRCV and CD or WD strains of BCV and to detect nasal and fecal shedding

\footnotetext{
*Present address: College of Veterinary Medicine, Chonnam National University, Kwangju 500-757, South Korea.

**Permanent address: Istanbul University, Veterinary Faculty, Department of Microbiology, Avcilar, 34851, Istanbul, Turkey.

*** Present address: EISO, Bacterial Zoonoses Branch, Centers of Disease Control and Prevention's National Center for Infectious Diseases, Division, Fort Collins, CO, U.S.A.
} 
of BCV using the 1-step RT-PCR, nested PCR and antigen-capture ELISA, 6 colostrum-deprived and two gnotobiotic calves were inoculated with a BRCV, a CD or a WD strain of BCV and then challenged 3-4 weeks later with either $\mathrm{BRCV}, \mathrm{CD}$ or WD strains of BCV. All calves developed diarrhea after inoculation and BCV antigen (ELISA) or RNA (RT-PCR) was detected in the diarrheic fecal samples or the corresponding nasal swab samples. In addition, low amounts of BCV were also detected only by nested PCR in the fecal and nasal swab samples before and after diarrhea. No respiratory clinical signs were observed during the entire experimental period, but elevated rectal temperatures were detected during diarrhea in the $\mathrm{BCV}$-inoculated calves. All calves recovered from infection with the $\mathrm{BRCV}, \mathrm{CD}$, or WD strains of $\mathrm{BCV}$ were protected from $\mathrm{BCV}$-associated diarrhea after challenge exposure with either a heterologous or homologous strain of BCV. However, all calves challenged with heterologous BCV strains showed subclinical BCV infection evident by detection of nasal and fecal shedding of BCV RNA detected only by nested PCR. Such results confirm field and experimental data documenting reinfection of the respiratory and enteric tracts of cattle, suggesting that, in closed herds, respiratory or enteric tract reinfections may constitute a source of BCV transmissible to cows (WD) or neonatal or feedlot calves. In addition, the present 1-step RT-PCR and nested PCR assays were highly sensitive to detect $\mathrm{BCV}$ in nasal swab and fecal specimens. Therefore, these assays should be useful to diagnose BCV infections in calves and adult cows.

\section{Introduction}

Bovine coronavirus (BCV), a member of the Coronaviridae family, causes severe diarrhea in newborn calves (CD) and is associated with winter dysentery (WD) in adult cattle $[2,20]$. The BCV possesses a single-stranded, non-segmented RNA genome of positive polarity [6]. The virion contains four major structural proteins: the nucleocapsid $(\mathrm{N})$ protein, the transmembrane $(\mathrm{M})$ protein, the hemagglutinin/esterase (HE) protein and the spike (S) protein [24]. The BCV N protein is a 50-kd phosphoprotein that binds viral genomic RNA to form the helical nucleocapsid [12]. The $\mathrm{N}$ protein may play a role in replication of viral RNA, since antibody directed against the $\mathrm{N}$ protein inhibits the in vitro RNA polymerase reaction [3]. The $\mathrm{N}$ protein of $\mathrm{BCV}$ shows an overall amino acid sequence identity of $70 \%$ with mouse hepatitis virus, a member of the same coronavirus serogroup 2 , but only $29 \%$ identity with the $\mathrm{N}$ protein of transmissible gastroenteritis virus and infectious bronchitis virus, members of coronavirus serogroups 1 and 3 , respectively [12].

Although diarrhea is recognized as the main clinical feature of BCV infections, BCV also causes respiratory tract infections in calves. Results of comparative studies indicated that coronaviruses isolated from either the intestinal or respiratory tract of calves replicated in both the intestinal and upper respiratory tracts of gnotobiotic or colostrum-deprived (Cols-D) calves [21]. Bovine respiratory coronavirus (BRCV) strains were frequently detected by ELISA and isolated from nasal swab samples of feedlot cattle with respiratory tract 
disease after shipping $[9,13,22,25]$. Thus BRCV infection may contribute to the bovine respiratory disease complex, which is the single most important syndrome affecting 6- to 10-month-old beef cattle after entry into feedlots in North America [16]. There are reports $[9,25]$ that BCV strains isolated from the respiratory tract had different biological and antigenic properties from BCV strains isolated from the enteric tract, whereas others reported no differences between enteric and respiratory BCV strains $[18,26]$. Fukutomi et al. [8] found that the $\mathrm{BRCV}$ and bovine enteric coronavirus (BECV) isolated from the respiratory and enteric tracts of a cow with winter dysentery, respectively, belonged to different antigenic groups according to their reactivity against monoclonal antibodies to the spike glycoprotein. However, in another report by Zhang et al. [32], they found a specific BRCV strain was genetically similar to enteric coronaviruses, with $98.7 \%$ nucleotide similarity of the spike gene sequence between the BRCV and BECV isolates. Others reported that calves, which recovered from infection with the $\mathrm{CD}$ or WD strain of $\mathrm{BCV}$, were protected from $\mathrm{BCV}$-associated diarrhea after challenge exposure with either the $\mathrm{CD}$ or WD strain of $\mathrm{BCV}[7,21]$, but nasal shedding of BCV was detected in 2 of 4 calves. To our knowledge, there are no in vivo cross-protection studies between $\mathrm{BRCV}, \mathrm{CD}$ and $\mathrm{WD}$ strains of $\mathrm{BCV}$.

A high degree of sensitivity is required to detect $\mathrm{BCV}$, especially from nasal specimens of cattle early or late in the course of illness when they may have transient low levels of viral shedding and may also have preexisting antibodies to BCV either passively or actively acquired. Although calves that recovered from experimental infection with the $\mathrm{CD}$ or WD strain of $\mathrm{BCV}$ were protected from $\mathrm{BCV}$-associated diarrhea after challenge exposure with either the $\mathrm{CD}$ or WD strain of BCV, nasal shedding was detected by ELISA from PCD 2 or 3 and persisted for 2 to 4 days in 2 of 4 calves challenge-exposed to heterologous $\mathrm{BCV}$ strains, suggesting that in closed herds, respiratory tract reinfections may constitute a source of BCV transmissible to cows (WD) or young calves [21]. Moreover, there is a report that chronic shedding of BCV in feces was observed in clinically normal cows [4]. Similarly, specificity is equally important to avoid false-positives. Silva et al. [22] reported detection of BRCV using an ELISA that demonstrated high specificity $(95.4 \%)$, but lower sensitivity $(76.5 \%)$. Therefore, more sensitive tests are required to detect BRCV in nasal swab samples to improve the diagnosis of BRCV infections and to examine repeat infections with homologous or heterologous BCV strains.

The RT-PCR assay is useful to detect small quantities of nucleic acids and it is widely used for the diagnosis of infectious diseases. The RT-PCR amplification of BCV RNA from fecal specimens has been described and its sensitivity has been reported [28]. The use of RT-PCR and nested PCR as a diagnostic tool for BRCV and its comparison with other routine diagnostic methods such as ELISA has not been reported to our knowledge. The purpose of our study was to investigate the in vivo cross-protection between BRCV (930), CD (DB2) and WD (DBA) strains of BCV and the occurrence of reinfections detected by RT-PCR and nested PCR. We also developed a simple 1-step RT-PCR and a nested PCR to detect BRCV in nasal swab as well as fecal specimens from calves experimentally infected with 
$\mathrm{CD}$, WD and BRCV strains of BCV and compared their sensitivity with that of an antigen-capture ELISA previously developed by our laboratory.

\section{Materials and methods}

\section{Reference viruses and cells}

The human rectal adenocarcinoma (HRT-18) cells were used for virus propagation. The BCV strains which were passaged as previously described [9] in HRT-18 cells included calf diarrhea (CD) strains (Mebus, DB2, 216XF, OHC, SDC), winter dysentery (WD) strains from adult cows (DBA, SD, BM, CN, AW, TS, BE, BW) and bovine respiratory coronavirus (BRCV) strains from feedlot cattle (BRCV 67, 76, 117, 220, 228, 255, 265, 430, 440, 930) [9, 27]. The growth medium was Eagle's minimum essential medium (EMEM) supplemented with $5 \%$ fetal bovine serum, $1 \%$ antibiotics (penicillin, dihydrostreptomycin, and mycostatin) and $1 \% \mathrm{NaHCO}_{3}$. The maintenance medium was EMEM supplemented with $1 \%$ antibiotics and $1 \% \mathrm{NaHCO}_{3}$.

\section{Virus titration}

Virus titration was performed using HRT-18 cell cultures grown in 96 well microplates [26]. For virus titration, serial 10 -fold dilutions of viruses were made in maintenance medium. Four wells of HRT-18 cells were each inoculated with $0.1 \mathrm{ml}$ of each dilution, incubated for 4 to 6 days at $37 \mathrm{C}$ and examined for cytopathic effects (CPE). Infectivity titers were expressed as median tissue culture infectious doses $\left(\mathrm{TCID}_{50}\right) / 0.1 \mathrm{ml}$.

\section{Calves}

Six 1- to 10-day-old Cols-D and two 5- and 27-day-old gnotobiotic calves were used for these studies (Table 1). Four calves (Calf Nos. 1, 3, 4, and 5) were inoculated oronasally with $40 \mathrm{ml}$ of tissue culture supernatant of the BRCV 930 strain and challenge exposed 21 to 28 days later oronasally with $40 \mathrm{ml}$ of the mock-infected HRT-18 tissue culture supernatant (Calf No. 1), homologous BRCV (Calf No. 3), or a 20\% suspension of intestinal contents of a heterologous DB2 CD or DBA WD (Calf Nos. 4-6) BCV strain (Table 1), respectively. Two Cols-D and one gnotobiotic calf (Calf Nos. 2, 7 and 8) were inoculated oronasally with $40 \mathrm{ml}$ of mock-infected HRT-18 tissue culture supernatant, DB2 CD or DBA WD strains of $\mathrm{BCV}$, respectively and challenge-exposed 21 and 25 days later with the BRCV 930 strain. One gnotobiotic calf (Calf No. 8) was mock inoculated, then inoculated oronasally at 27 days of age with $40 \mathrm{ml}$ of the inactivated BRCV 930 strain (as mentioned later). All calves were fed human infant formula (Similac, Ross Laboratories, Columbus, Ohio).

\section{Clinical observations and specimen collection}

After inoculation and challenge exposure, respiratory signs, rectal temperatures and color and consistency of feces from each calf were evaluated daily. Feces were scored on a scale of $0-4$, with 0 representing firm; 1 , pasty; 2 , semimucoid; 3 , liquid and 4, profuse diarrhea. Nasal and fecal specimens were collected daily as described previously [7] for 21 days after inoculation and 15 days after challenge exposure. Blood samples were collected from each calf prior to inoculation and prior to challenge exposure, then 15 days later after challenge exposure (Table 1).

\section{BCV antigen ELISA}

An indirect antigen-capture ELISA employing monoclonal antibodies (Mabs) to BCV as capture antibodies (Abs) was used to detect BCV in nasal swab fluids and fecal suspensions 
as previously described $[13,23]$. Briefly, the plates were read at $414 \mathrm{~nm}$ using an ELISA reader, and the absorbances were saved as ASCII files. A spreadsheet program was used to calculate the ELISA values for the samples, by subtracting the average absorbance of the paired BCV antibody negative-coated wells from the average absorbance of the paired BCV antibody positive-coated wells. Samples with an absorbance of 0.03 or greater were considered to be positive for BCV antigen.

\section{Extraction of viral RNA}

To compare the sensitivity of the PCR based assay with ELISA, Mebus $\left(1 \times 10^{5}\right.$ $\left.\mathrm{TCID}_{50} / 0.1 \mathrm{ml}\right), \mathrm{BRCV}-255\left(1 \times 10^{8} \mathrm{TCID}_{50} / 0.1 \mathrm{ml}\right)$, and BRCV-440 $\left(1 \times 10^{8} \mathrm{TCID}_{50} / 0.1 \mathrm{ml}\right)$ strains were serially diluted 10 -fold in either maintenance medium or normal nasal swab suspensions from preexposure gnotobiotic calves. RNA was extracted based on the acid guanidinium-phenol-chloroform RNA extraction method [1]. Briefly, $500 \mu 1$ Solution D (4 M guanidinium thiocyanate, $25 \mathrm{mM}$ Sodium citrate, $\mathrm{pH} 7,0.5 \%$ sarcosyl, $0.1 \mathrm{M} 2$ mercaptoethanol) and $50 \mu \mathrm{l} 2 \mathrm{M}$ sodium acetate ( $\mathrm{pH} 4.0)$ were added to individual tubes containing $200 \mu \mathrm{l}$ of each of the above serially 10 -fold diluted BCV specimens, fecal suspensions diluted 1:25 with maintenance medium, or nasal swab samples. After mixing, $500 \mu \mathrm{l}$ of water saturated phenol ( $\mathrm{pH} 4.5)$ and $100 \mu \mathrm{l}$ of chloroform and isoamylalcohol (49:1) were added, vortexed briefly and placed on the ice for $15 \mathrm{~min}$. The mixture was centrifuged at $20,800 \mathrm{~g}$ for $20 \mathrm{~min}$ at $4 \mathrm{C}$ and the supernatant was transferred into a new tube. To remove non-specific inhibitors of the PCR reaction present in the extracted samples, the supernatant was purified using the Rnaid kit according to the manufacturer's instructions (BIO 101, Inc., La Jolla, CA). The extracted RNA was resuspended with $50 \mu 1$ DEPC treated water. As negative controls, RNA was extracted from mock-infected HRT-18 cells, nasal swab suspensions from preexposure gnotobiotic calves, swine testicular cells infected with the Miller strain of transmissible gastroenteritis coronavirus and Rhesus monkey kidney cells infected with bovine rotavirus OK strain.

\section{Virus inactivation}

To assess the possibility that the RT-PCR or nested PCR were detecting residual BCV inoculum after inoculation or challenge, we inoculated a gnotobiotic calf (Calf No. 8) with inactivated BRCV to study virus shedding. The BRCV 930 strain was inactivated by chloroform treatment. Briefly, $50 \mathrm{ml}$ of infected HRT-18 tissue culture supernatant containing the BRCV 930 strain was mixed with $2.5 \mathrm{ml}$ of chloroform (Amersco Inc. Solon, OH, USA). This mixture was agitated for $10 \mathrm{~min}$ at $4 \mathrm{C}$ and centrifuged at $400 \mathrm{~g}$ for $5 \mathrm{~min}$ at $4 \mathrm{C}$. The upper layer supernatant was used for virus inoculum after allowing the residual chloroform to evaporate.

To assess the lowest detection limit of the PCR based assays and ELISA for inactivated virus, the inactivated BRCV-440 $\left(1 \times 10^{8} \mathrm{TCID}_{50} / 0.1 \mathrm{ml}\right)$ strain was serially diluted 10 -fold in normal nasal swab suspensions from preexposure gnotobiotic calves. RNA was extracted using the acid guanidinium-phenol-chloroform RNA extraction method as mentioned earlier.

\section{Preparation of oligonucleotide primers}

The oligonucleotide primers used in the RT-PCR and nested PCR were designed from the published sequence of the $\mathrm{N}$ gene of the Mebus strain (GenBank accession No. M16620). The sequence of primers (positions calculated from the start codon of the nucleocapsid gene) were as follows: upstream primer for RT-PCR, 5'-GCAATCCAGTAGTAGAGCGT-3' (21-40); downstream primer for RT-PCR, 5'CTTAGTGGCATCCTTGCCAA-3' (731-750); upstream primer for nested PCR, 5'-GCCGATCAGTCCGACCAATG-3' (79-98); downstream primer 
for nested PCR, 5'-AGAATGTCAGCCGGGGTAG-3' (467-485). The predicted RT-PCR and nested PCR products were 730 and 407 base pairs, respectively.

\section{$R T-P C R$}

The conventional RT-PCR assay was performed with minor modifications as described previously [28]. The reverse transcriptase reaction was conducted as follows. In the tube, $10 \mu \mathrm{l}$ of RNA sample was added to $2 \mu \mathrm{l}$ of the downstream primer (50 pmol). The tube was incubated at $100 \mathrm{C}$ for $2 \mathrm{~min}$ and then quenched on ice for $5 \mathrm{~min}$. Subsequently, $4 \mu \mathrm{l}$ of $5 \times \mathrm{RT}$ buffer [250 mM tris- $\mathrm{HCl}$ (pH8.3), $375 \mathrm{mM} \mathrm{KCl}, 15 \mathrm{mM} \mathrm{MgCl}_{2}$ ], $1 \mu \mathrm{l}$ of $0.1 \mathrm{M}$ dithiothereitol, $2 \mu \mathrm{l}$ of $10 \mathrm{mM}$ dNTPs, $0.5 \mu \mathrm{l}$ of RNAsin (Promega Corporation), and $0.5 \mu \mathrm{l}$ of AMV RT (Promega Corporation) were added and incubated at $37 \mathrm{C}$ for $60 \mathrm{~min}$. Then $10 \mu \mathrm{l}$ of the RT reaction samples were added to $40 \mu \mathrm{l}$ of the PCR mixture. The PCR mixture consisted of $5 \mu \mathrm{l}$ of $10 \times$ buffer [100 mM Tris- $\mathrm{HCl}(\mathrm{pH} 8.3), 500 \mathrm{mM} \mathrm{KCl}, 15 \mathrm{mM} \mathrm{MgCl}_{2}, 0.01 \%$ gelatin], $1 \mu \mathrm{l}$ of $10 \mathrm{mM}$ dNTPs, $0.5 \mu \mathrm{l}$ of the upstream primer ( $50 \mathrm{pmol}), 0.5 \mu \mathrm{l}$ of the downstream primer ( $50 \mathrm{pmol}), 32.5 \mu \mathrm{l}$ of water and $0.5 \mu \mathrm{l}$ of Taq polymerase (Promega Corporation) $(5 \mathrm{U} / \mu \mathrm{l})$. The mixture was overlaid with mineral oil and then subjected to 5 min of preheating at $94 \mathrm{C}$, 35 cycles of $1 \mathrm{~min}$ at $94 \mathrm{C}, 1 \mathrm{~min}$ at $58 \mathrm{C}, 2 \mathrm{~min}$ at $72 \mathrm{C}$ and a final $7 \mathrm{~min}$ incubation at $72 \mathrm{C}$. The PCR products were visualized on $1.5 \%$ agarose gels stained with ethidium bromide.

To develop a simple and more rapid method for the detection of BCV RNA, a 1-step RT-PCR assay was performed with modifications as described previously [31]. The tube containing $5 \mu \mathrm{l}$ of the RNA sample and $1 \mu \mathrm{l}$ of DMSO was incubated at $70 \mathrm{C}$ for $10 \mathrm{~min}$ and then quenched on ice. Subsequently, $44 \mu 1$ of the RT-PCR mixture was added. The RT-PCR mixture consisted of $5 \mu \mathrm{l}$ of $10 \times$ buffer [ $100 \mathrm{mM}$ Tris- $\mathrm{HCl}(\mathrm{pH} 8.3), 500 \mathrm{mM} \mathrm{KCl}, 15 \mathrm{mM}$ $\mathrm{MgCl}_{2}, 0.01 \%$ gelatin], $5 \mu \mathrm{l}$ of $\mathrm{MgCl}_{2}(25 \mathrm{mM}), 1 \mu \mathrm{l}$ of $10 \mathrm{mM}$ dNTPs, $1 \mu l$ of the upstream primer (50 pmol), $1 \mu \mathrm{l}$ of the downstream primer (50 pmol), $0.5 \mu \mathrm{l}$ of RNAsin (Promega Corporation), and $0.5 \mu \mathrm{l}$ of AMV RT (Promega Corporation), $0.5 \mu \mathrm{l}$ of Taq polymerase (Promega Corporation) $(5 \mathrm{U} / \mu \mathrm{l})$. The mixture was incubated for $60 \mathrm{~min}$ at $42 \mathrm{C}$, preheated for $5 \mathrm{~min}$ at $94 \mathrm{C}$, subjected to 35 cycles of $1 \mathrm{~min}$ at $94 \mathrm{C}, 1 \mathrm{~min}$ at $58 \mathrm{C}, 2 \mathrm{~min}$ at $72 \mathrm{C}$ and a final $7 \mathrm{~min}$ incubation at $72 \mathrm{C}$. The PCR products were visualized on $1.5 \%$ agarose gels stained with ethidium bromide.

\section{Nested PCR}

For increasing the sensitivity and specificity of the RT-PCR, $5 \mu$ of diluted RT-PCR products (1:100) were added to a tube containing $45 \mu \mathrm{l}$ of the PCR mixture (final dilution of 1,000 times). If the predicted band was absent by RT-PCR, $5 \mu$ l of undiluted RT-PCR product was subjected directly to nested PCR. The PCR mixture consisted of $5 \mu 1$ of $10 \times$ buffer $[100 \mathrm{mM}$ Tris- $\mathrm{HCl}(\mathrm{pH} 8.3), 500 \mathrm{mM} \mathrm{KCl}, 15 \mathrm{mM} \mathrm{MgCl} 2,0.01 \%$ gelatin], $5 \mu$ of $\mathrm{MgCl}_{2}(25 \mathrm{mM}$ ), $1 \mu \mathrm{l}$ of $10 \mathrm{mM}$ dNTPs, $1 \mu \mathrm{l}$ of the nested PCR upstream primer (50 pmol), $1 \mu 1$ of the nested PCR downstream primer $(50 \mathrm{pmol}), 0.5 \mu \mathrm{l}$ of Taq polymerase (Promega corporation) $(5 \mathrm{U} / \mu \mathrm{l})$ and $31.5 \mu \mathrm{l}$ water. The mixture was preheated for $5 \mathrm{~min}$ at $94 \mathrm{C}$, subjected to 30 cycles of $1 \mathrm{~min}$ at $94 \mathrm{C}, 1 \mathrm{~min}$ at $58 \mathrm{C}, 2 \mathrm{~min}$ at $72 \mathrm{C}$ and a final $7 \mathrm{~min}$ incubation at $72 \mathrm{C}$. The PCR products were visualized on $1.5 \%$ agarose gels stained with ethidium bromide. As a negative control, RT-PCR products with RNA extracted from mock-infected HRT-18 cells was used.

\section{BCV antibody ELISA}

An antibody-detection ELISA previously developed by Lathrop et al. [13] for BRCV and by Smith et al. [23] for enteric BCV was performed to detect IgG antibodies to BCV in serum samples from experimental calves. The plates were read at $414 \mathrm{~nm}$ using an ELISA reader, and the absorbances were saved as ASCII files. A spreadsheet program was used to 
calculate the ELISA values for the samples, by subtracting the average absorbance of a row of wells coated with mock-infected cell culture supernatant from the average absorbance of the BCV-coated wells at each dilution for each sample. The titer was determined to be the serum dilution at which the mean absorbance of the positive wells was 0.1 greater than the mean absorbance of the negative wells.

\section{Data analysis}

The percent observed agreement, sensitivity and specificity for ELISA compared to RT-PCR and nested PCR was calculated for nasal and fecal samples from the experimental calves [15]. A Kappa value was calculated to determine the agreement beyond chance between the ELISA and RT-PCR and the ELISA and nested PCR. When $\kappa=0$ there is no agreement beyond chance levels: when $\kappa<0.3$ the agreement is poor. A value of $\kappa$ between 0.3 and 0.5 is acceptable, between 0.5 and 0.7 is good, and $>0.7$ is excellent [17].

\section{Results}

\section{Development of RT-PCR and nested PCR}

The RT-PCR was first standardized with RNA isolated from the tissue culture propagated BCV strains (5 CD strains, $8 \mathrm{WD}$ strains, and $10 \mathrm{BRCV}$ strains). A specific $730 \mathrm{bp}$ band was detected after amplification with all $5 \mathrm{CD}, 8 \mathrm{WD}$ and 10 BRCV strains (Fig. 1A). To increase sensitivity, nested PCR was performed with the RT-PCR products. PCR products of $407 \mathrm{bp}$ were detected after nested PCR with all $5 \mathrm{CD}, 8 \mathrm{WD}$ and $10 \mathrm{BRCV}$ strains of BCV (Fig. 1B). To study

(A)
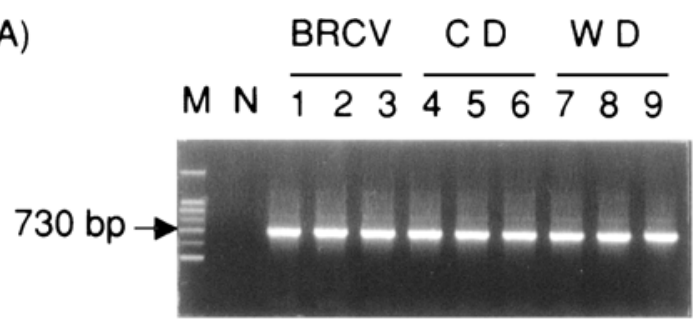

(B)
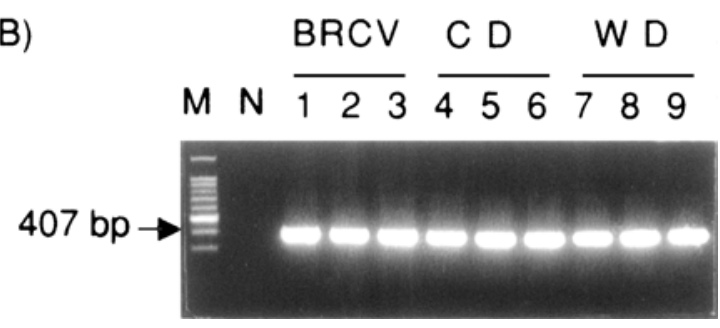

Fig. 1. Specificity of the primers for the detection of respiratory coronavirus (BRCV), calf diarrhea (CD) and winter dysentery (WD) strains of bovine coronavirus (BCV). A The 1-step RT-PCR assay products of BRCV (1-3), CD (4-6) and WD (7-9) strains of BCV. B The nested PCR products with 1-step RT-PCR products of BRCV (1-3), CD (4-6) and WD (7-9) strains. $M$ Marker. $N$ Mock-infected HRT-18 cells. 1-3 BRCV 255, 440 and 930 strains, respectively. 4-6 CD Mebus, DB2 and OHC strains, respectively. 7-9 WD DBA, SD and BM strains, respectively 
the specificity of the primers, PCR was also performed with RNA extracted from rotavirus, transmissible gastroenteritis coronavirus, mock-infected HRT-18 cells, and BCV negative nasal swab suspensions from preexposure gnotobiotic calves. The RT-PCR and nested PCR detected no bands in these control RNA samples.

To develop a simpler RT-PCR assay, the RT reaction and PCR were performed in the same tube (1-step RT-PCR). The BRCV $220\left(1 \times 10^{8} \mathrm{TCID}_{50} / 0.1 \mathrm{ml}\right)$ and $440\left(1 \times 10^{8} \mathrm{TCID}_{50} / 0.1 \mathrm{ml}\right)$ strains and CD Mebus strain $\left(3 \times 10^{8} \mathrm{TCID}_{50} / 0.1 \mathrm{ml}\right)$ were serially diluted tenfold and the sensitivity of 1-step RT-PCR was compared with that of conventional RT-PCR in which the RT and PCR were done in separate tubes. The lowest detection limit of the 1-step RT-PCR as determined by using serial dilutions was $2 \times 10^{4} \mathrm{TCID}_{50} / 0.1 \mathrm{ml}$ with both BRCV 220 and 440 strains and $6 \times 10^{4} \mathrm{TCID}_{50} / 0.1 \mathrm{ml}$ with the CD Mebus strain (Fig. 2A). The sensitivity of the 1-step RT-PCR was consistent with that of the conventional RT-PCR in which RT and PCR were done separately.

Nested PCR was performed using the amplified products from the 1-step RT-PCR with extracted RNA from each serial dilution of the BRCV 220 and 440 strains and CD Mebus strain. The lowest detection limit of the nested PCR was $2 \times 10^{2} \mathrm{TCID}_{50} / 0.1 \mathrm{ml}$ with both BRCV 220 and 440 strains and $6 \times 10^{2}$ $\mathrm{TCID}_{50} / 0.1 \mathrm{ml}$ with the CD Mebus strain (Fig. 2B).

Fecal samples could have non-specific inhibitors of the PCR reaction [30]. The sensitivity of RT-PCR using BCV diluted in fecal suspensions was 10-fold lower in comparison with that of RT-PCR using BCV diluted in medium or PBS (data not shown). To investigate the possibility that non-specific inhibitors of the PCR reaction in nasal swab suspensions could influence the assay sensitivity, each BRCV 220 and 440 strain and CD Mebus strain was serially diluted tenfold in $\mathrm{BCV}$ negative nasal swab suspensions from preexposure gnotobiotic calves
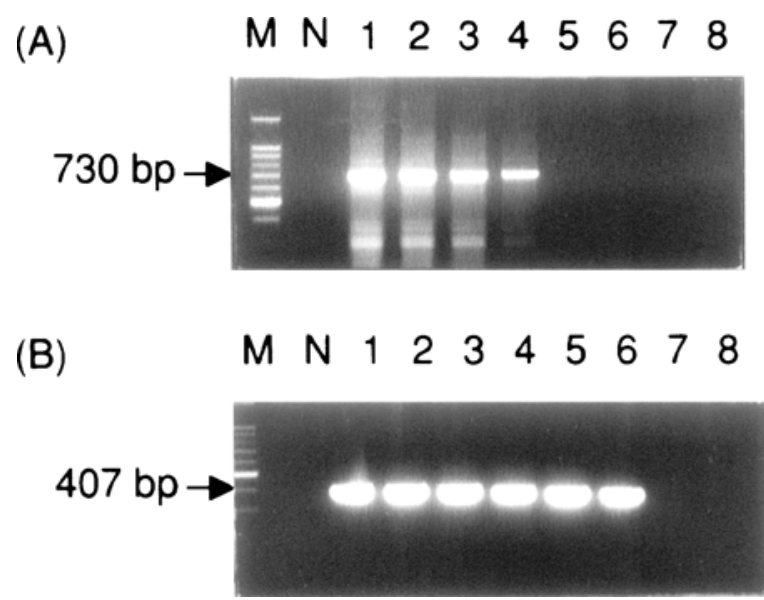

Fig. 2. Sensitivity of RT-PCR and nested PCR assays. A 1-step RT-PCR was performed in the same tube with serially diluted BRCV 255 strain. B Nested PCR products with 1-step RT-PCR products. $M$ Marker. $N$ Mock-infected HRT-18 cells. Lanes 1-8: $2 \times 107,2 \times 106$, $2 \times 105,2 \times 104,2 \times 103,2 \times 102,2 \times 101,2$ TCID50/0.1 ml, respectively 
and the 1-step RT-PCR and nested PCR were performed. Assay sensitivity was compared with that of 1-step RT-PCR with RNA extracted from BCV serially diluted in maintenance medium. The RNA of BCV diluted with either maintenance medium or nasal swab suspensions was extracted using the Rnaid kit in which possible non-specific inhibitors of the PCR reaction were removed from the RNA matrix. The lowest detection limit of 1-step RT-PCR or nested PCR with RNA extracted from BCV diluted in either maintenance medium or nasal swab suspensions was the same as mentioned earlier for each respective assay.

To confirm whether inactivation decreased the sensitivity of ELISA, 1-step RT-PCR and nested PCR assays were performed using serial dilutions of the inactivated BRCV 440 strain. The lowest detection limit of these methods was consistent with that of the original non-inactivated BRCV 440 strain.

\section{Comparison of the sensitivity of capture ELISA, 1-step RT-PCR and nested PCR}

In order to compare the sensitivity of the PCR based assays with the antigen capture ELISA, BRCV $220\left(1 \times 10^{8} \mathrm{TCID}_{50} / 0.1 \mathrm{ml}\right)$ and $440\left(1 \times 10^{8} \mathrm{TCID}_{50} / 0.1 \mathrm{ml}\right)$ strains and CD Mebus strain $\left(3 \times 10^{8} \mathrm{TCID}_{50} / 0.1 \mathrm{ml}\right)$ which were grown in HRT18 cells were serially diluted in either maintenance medium or BCV negative nasal swab suspensions from preexposure gnotobiotic calves and both PCR assays and antigen capture ELISA were performed. The lowest detection limit of antigen capture ELISA with samples from BCV diluted with maintenance medium was $1 \times 10^{5} \mathrm{TCID}_{50} / 0.1 \mathrm{ml}$ with the BRCV 220 and 440 strains and $3 \times 10^{5} \mathrm{TCID}_{50} / 0.1 \mathrm{ml}$ with the CD Mebus strain, respectively. When the BCV was diluted in nasal swab suspensions there was a ten-fold decrease in sensitivity. The RT-PCR and nested PCR, using the dilution of BCV in nasal swab suspensions gave an approximately 50- and 5000-fold increase in sensitivity compared to antigen capture ELISA for the nasal swab suspensions.

\section{Clinical signs of disease, nasal and fecal shedding of $B C V$ and $\operatorname{Ig} G$ antibody titers to $B C V$ in calf sera}

Six Cols-D and 1 gnotobiotic calf were inoculated with BRCV, CD and WD strain of BCV and calves were challenge exposed with the homologous or heterologous $\mathrm{BCV}$ (Tables 1 and 2) to investigate their in vivo cross-protection and the onset and duration of nasal and fecal shedding of BCV. The fecal and nasal swab samples were tested by antigen-capture ELISA, RT-PCR and nested PCR (Tables 1 and 2). No calves showed any respiratory signs after inoculation or challenge exposure with the BCV strains. Elevated body temperatures were observed only during diarrhea.

One gnotobiotic calf was inoculated with the inactivated BRCV 930 strain of BCV. The fecal and nasal swab samples were collected for 10 days and tested by ELISA, RT-PCR and nested PCR to detect BCV. No clinical signs including elevated body temperatures, respiratory or enteric disease were observed. The $\mathrm{BCV}$ was not detected in any samples by ELISA, RT-PCR and nested PCR, suggesting 


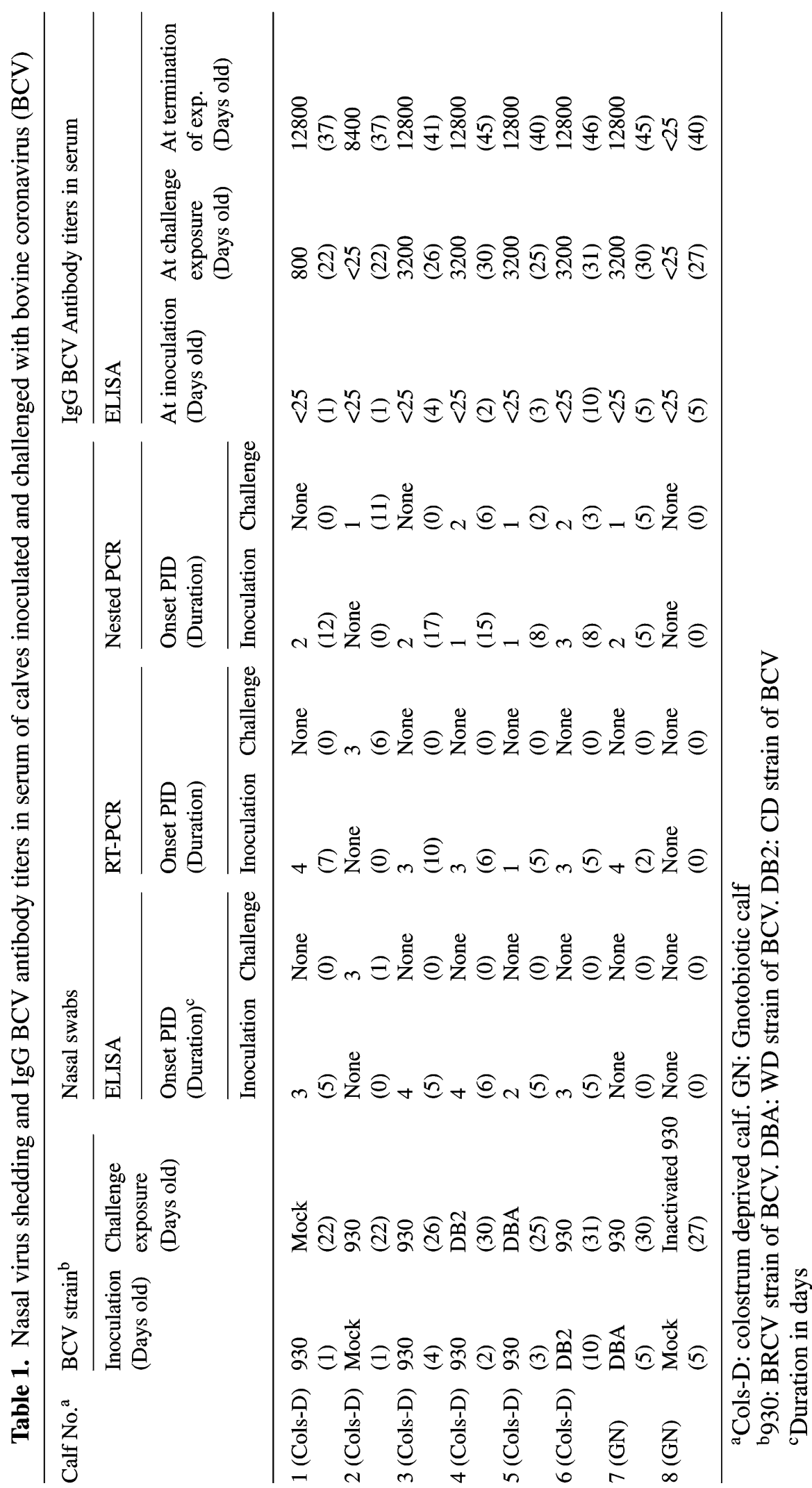




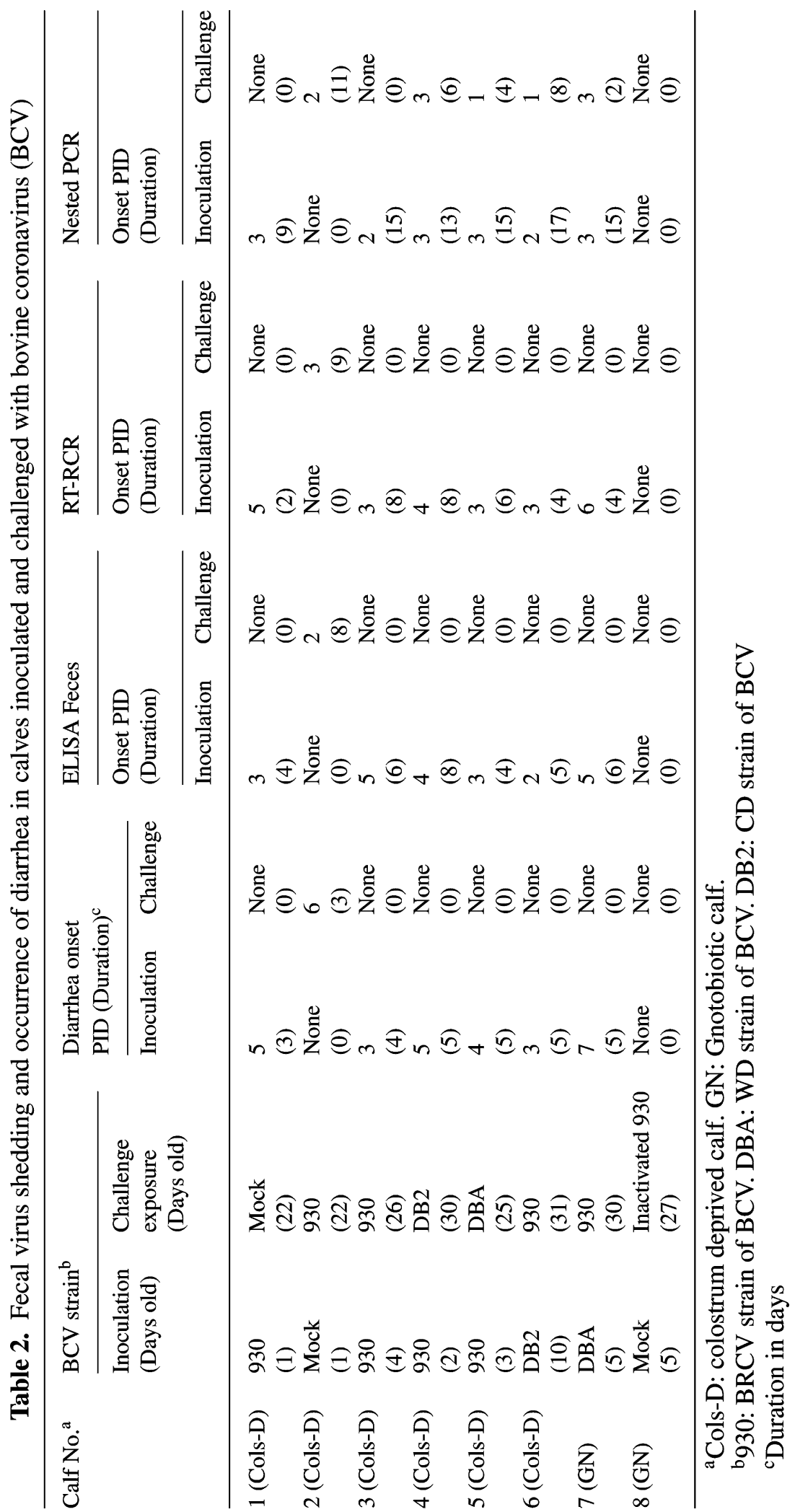


that the BCV detected in the nasal and fecal specimens of the inoculated calves represented replicating virus and not merely collection of the virus inoculum in the nasal secretions or feces.

By ELISA, nasal shedding of BCV was detected in 5 of $6 \mathrm{BCV}$-inoculated Col-D calves by PID 3-4 and shedding persisted for 5-6 days, intermittently. By RT-PCR all BCV-inoculated calves shed BCV nasally by PID 3-4, which persisted for 2-10 days, intermittently (Fig. 3A). By nested PCR, nasal shedding of BCV was detected in all BCV-inoculated calves by PID 1 to 3 and it persisted intermittently for 5-17 days until PID 19 (Fig. 3B \& Table 1). Except for mock challenge-exposed Calf No. 1, no nasal shedding of BCV after challenge exposure was detected by ELISA or RT-PCR. However, by nested PCR, all challengeexposed calves, except the homologous virus (Calf No. 3), inactivated virus (Calf No. 8) and mock challenged-exposed (Calf No. 1) calves, showed nasal virus shedding by PID 1 that persisted intermittently for 3 to 11 days.
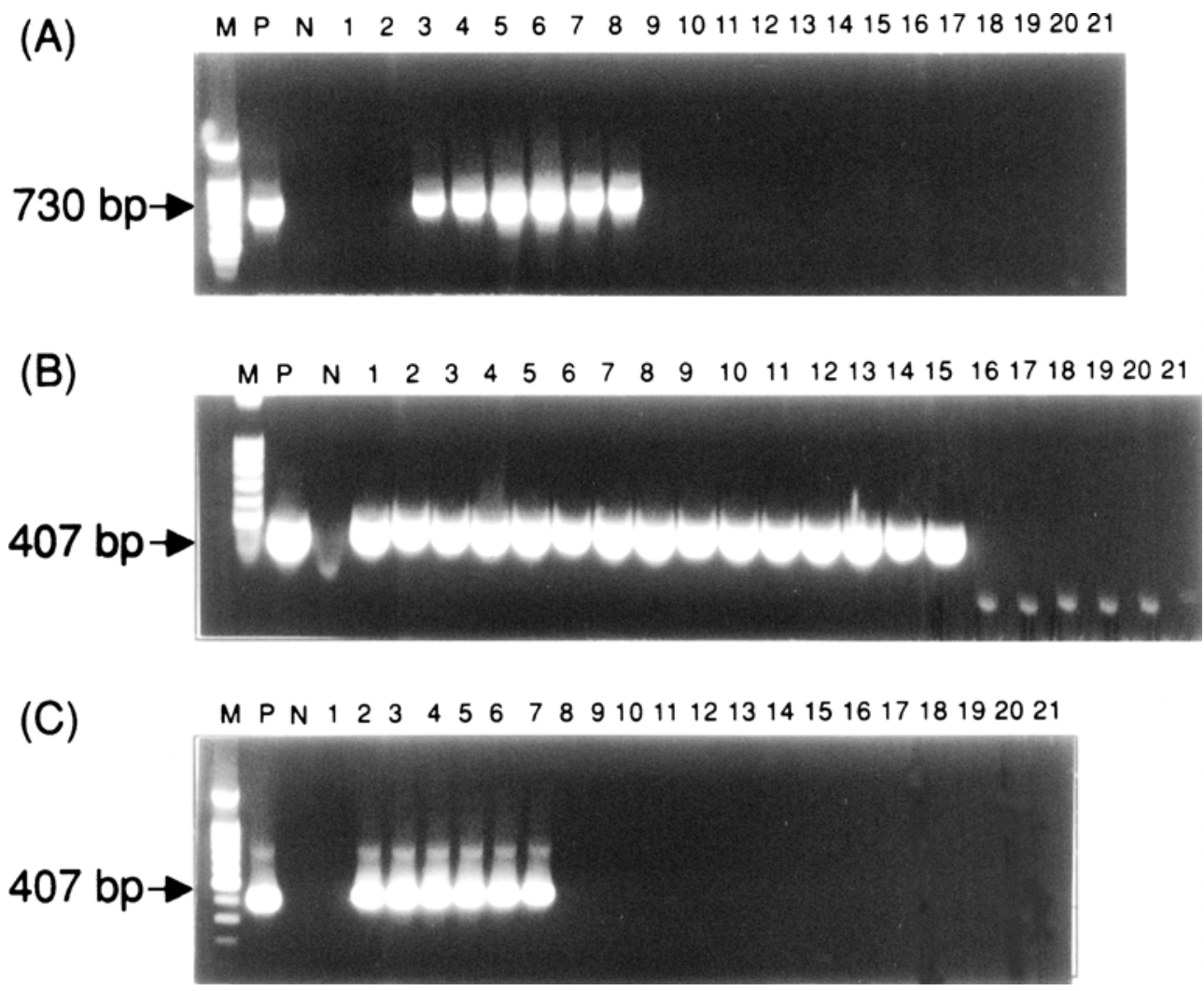

Fig. 3. RT-PCR and nested PCR detection of BCV RNA in nasal swab samples from a calf (Calf No. 4) experimentally inoculated with BRCV 930 and challenge exposed with DB2. A RT-PCR results with samples obtained after inoculation. B Nested PCR results with samples obtained after inoculation. C Nested PCR results with samples obtained after challenge exposure. Top numbers indicate postinoculation days $(\mathbf{A} \& \mathbf{B})$ and challenge exposure days C. $M$ Molecular marker. $P$ BRCV 930 strain-infected HRT-18 cells. $N$ Mock-infected HRT-18 cells 
By PID 3 to 7, all BCV-inoculated calves developed profuse watery diarrhea that persisted for 3 to 5 days. The BCV antigen was detected in feces by ELISA from PID 2 to 5 and shedding persisted for 4 to 6 days. By RT-PCR, all BCV inoculated calves shed BCV in feces by PID 3 to 6 and shedding persisted for 2 to 8 days. By nested PCR, fecal shedding of BCV could be detected in all inoculated calves by PID 2 to 3 and persisted intermittently for 17 days (Fig. 3C).

After challenge exposure, only the mock-inoculated, BRCV 930 challengeexposed calf No. 2 developed diarrhea and fecal shedding and, no diarrhea or fecal shedding of BCV detected by ELISA or RT-PCR occurred in any of the other BCVchallenged calves. By nested PCR, however, all calves except the homologous virus (Calf No. 3), inactivated virus (Calf No. 8) and mock challenged-exposed (Calf No. 1) calves, had fecal shedding of BCV by PID 1 to 3 for 2-11 days.

Twenty-four swab samples (8.9\%) were positive by both ELISA and RT-PCR; 17 samples $(6.3 \%)$ were positive by RT-PCR and negative by ELISA; 2 (1.1\%) were positive by ELISA and negative by RT-PCR; and 224 (83.5\%) were negative by both tests (Table 3a). The percentage of agreement between the 2 assays was 92.5\%. The sensitivity and specificity of RT-PCR compared with ELISA were $88.8 \%$ and $92.9 \%$, respectively. The agreement beyond chance was calculated with a Kappa statistic, which was $\kappa=0.66$ for these data.

Twenty-seven nasal swab samples $(10.0 \%)$ were positive by both ELISA and nested PCR; 64 samples (23.8\%) were positive by nested PCR and negative by ELISA; no samples were positive by ELISA and negative by nested PCR; and $177(66.0 \%)$ were negative by both tests (Table $3 \mathrm{~b})$. The percentage of agreement between the 2 assays was $74.1 \%$. The sensitivity and specificity of nested PCR compared with ELISA were $100 \%$ and $73.4 \%$, respectively. The agreement beyond chance calculated with a Kappa statistic was $\kappa=0.35$.

Thirty-four fecal samples (12.6\%) were positive by both ELISA and RT-PCR; 7 samples $(2.6 \%)$ were positive by RT-PCR and negative by ELISA; $6(2.2 \%)$ were positive by ELISA and negative by RT-PCR; and 221 (82.4\%) were negative by both tests (Table 3c). The percentage of agreement between the 2 assays was 95.1\%. The sensitivity and specificity of RT-PCR compared with ELISA were $81.0 \%$ and $96.6 \%$, respectively. The agreement beyond chance calculated with a Kappa statistic was $\kappa=0.81$.

Forty fecal samples (14.9\%) were positive by both ELISA and nested PCR; 76 samples $(28.3 \%)$ were positive by nested PCR and negative by ELISA; no samples were positive by ELISA and negative by RT-PCR; and $152(56.7 \%)$ were negative by both tests (Table 3d). The percentage of agreement between the 2 assays was $71.6 \%$. The sensitivity and specificity of nested PCR compared with ELISA were $100 \%$ and $66.6 \%$, respectively. The agreement beyond chance calculated with a Kappa statistic was $\kappa=0.37$.

The IgG antibody titers in sera collected at inoculation, challenge exposure and termination of the experiment from inoculated and challengeexposed calves were determined by antibody capture ELISA (Table 1). No major differences in IgG antibody titers to BCV in the different inoculated and challenge-exposed calves (BRCV \& BRCV, BRCV \& CD, BRCV \& WD, CD 
Table 3. Analysis of sensitivity and specificity of antigen-capture ELISA, compared to RT-PCR and nested PCR for detection of bovine coronavirus in nasal swab and fecal samples from experimentally infected calves

a Comparison of antigen-capture ELISA and RT-PCR using nasal swab samples c Comparison of antigen-capture ELISA and RT-PCR using fecal samples

\begin{tabular}{ll|r|r|r}
\multicolumn{5}{c}{ Capture ELISA } \\
& & + & - & Total \\
RT- & + & 24 & 17 & 41 \\
PCR & - & 3 & 224 & 227 \\
\cline { 2 - 5 } & Total & 27 & 241 & 268
\end{tabular}

Percent observed agreement $(\mathrm{Po})=(24+224) /$ $268=92.5 \%$. Sensitivity $=24 / 27=88.8 \%$. Specificity $=224 / 241=92.9 \%$. Kappa $=0.66$
Capture ELISA

RT-

PCR

\begin{tabular}{l|r|r|r} 
& \multicolumn{1}{|c|}{+} & \multicolumn{1}{|c|}{ Total } \\
\hline+ & 34 & 7 & 41 \\
\hline- & 6 & 221 & 227 \\
\hline Total & 40 & 228 & 268
\end{tabular}

$\mathrm{Po}=(34+221) / 268=95.1 \%$. Sensitivity $=$ $34 / 40=81.0 \%$. Specificity $=221 / 228=$ $96.6 \%$. Карpa $=0.81$ b Comparison of antigen-capture ELISA and nested PCR using nasal swab samples d Comparison of antigen-capture ELISA and nested PCR using fecal samples

\section{Capture ELISA}

Nested PCR

\begin{tabular}{l|r|r|r} 
& \multicolumn{1}{|c|}{+} & \multicolumn{1}{|c|}{-} & Total \\
\hline+ & 27 & 64 & 91 \\
\hline- & 0 & 177 & 177 \\
\hline Total & 27 & 241 & 268
\end{tabular}

Po $=(27+177) / 268=76.1 \%$. Sensitivity $=$ $27 / 27=100 \%$. Specificity $=177 / 241=73.4 \%$. Kappa $=0.35$
Capture ELISA

Nested

PCR

\begin{tabular}{l|r|r|l} 
& + & \multicolumn{1}{|c|}{-} & Total \\
\hline+ & 40 & 76 & 116 \\
\hline- & 0 & 152 & 152 \\
\hline Total & 40 & 228 & 268
\end{tabular}

$\mathrm{Po}=(40+152) / 268=71.6 \%$. Sensitivity $=$ $40 / 40=100 \%$. Specificity $=152 / 228=66.6 \%$. Kappa $=0.37$

\& BRCV, or WD \& BRCV) were observed. No IgG antibodies to BCV were detected in serum by PID 13 in the calf (Calf No. 8) inoculated with inactivated BRCV 930.

\section{Discussion}

The RT-PCR amplification of BCV RNA from stool specimens has been described, but to our knowledge, there are no reports of the diagnosis of BCV in feces and nasal swabs by RT-PCR and nested PCR. We designed primers from the nucleocapsid gene of BCV because this gene is conserved among BCV strains [5]. All 5 CD, 8 WD and 10 BRCV strains were detected by RT-PCR, suggesting that the sequences of the primers used in this study were conserved among these clinically diverse BCV strains. Nested primers can further amplify the products of the RT-PCR reaction. The nested PCR primers used in this study amplified the predicted bands of $407 \mathrm{bp}$ from the RT-PCR products of all $5 \mathrm{CD}, 8 \mathrm{WD}$ and 10 BRCV strains of BCV. Moreover, primers used in this study for RT-PCR and nested PCR did not amplify RNA from rotavirus, transmissible gastroenteritis 
coronavirus, mock-infected HRT-18 cells, and nasal swab and fecal samples from preexposure gnotobiotic or Cols-D calves. From these results, primers used for RT-PCR and nested PCR in this study were specific for detecting BCV including $\mathrm{CD}$, WD and BRCV strains.

The assay protocol to detect BCV RNA should be as simple as possible such that it could be simultaneously applied to large numbers of clinical samples. Also, if possible, radioisotopes should be avoided as they are costly and difficult to use in many diagnostic laboratories. To accommodate these requirements, the reverse transcription and PCR amplification reactions were conducted sequentially in a single tube and the PCR products were detected by ethidium bromide staining following fractionation on an agarose gel. In the present study, the 1-step RT-PCR amplification in the same tube was of similar sensitivity for detection of BCV RNA to that of RT and PCR amplification steps, which were done in different tubes. From these results, the 1-step RT-PCR assay was useful for the detection of BCV in the fecal and especially the nasal swab samples.

The ideal method for detection of BCV in nasal swab samples should also have a high degree of sensitivity and consistency of performance in the laboratory. The antigen-capture ELISA with BRCV strains used in the present study could detect approximately $1 \times 10^{5}$ and $1 \times 10^{6} \mathrm{TCID}_{50} / 0.1 \mathrm{ml}$ of BCV in the BCV samples serially diluted with medium or normal nasal swab suspensions, respectively. The reason for this decrease in sensitivity when the antigen-capture ELISA is done using nasal swab suspensions is unclear but it possibly reflects the presence of blocking substances in the nasal swab suspensions, as in fecal suspensions [11, 29]. The lower sensitivity limit of RT-PCR and nested PCR with BRCV strains used in this study was $2 \times 10^{4}$ and $2 \times 10^{2} \mathrm{BCV} \mathrm{TCID}_{50} / 0.1 \mathrm{ml}$ of BCV in the $\mathrm{BCV}$ samples serially diluted with normal nasal swab suspensions. Comparison of the RT-PCR and nested PCR assays with antigen-capture ELISA showed that they are 50 and 5000 times more sensitive, respectively than ELISA.

Fecal samples could have non-specific inhibitors of the PCR reaction [30]. To remove non-specific inhibitors of the PCR reaction present in the nasal swab samples, we used the Rnaid kit according to the manufacturer's instructions (BIO 101, Inc. La Jolla, CA). Some of the positive samples (after RNA matrix treatment) were negative by RT-PCR if the RNA matrix was not used (data not shown) suggesting that possible non-specific inhibitors of the PCR reaction were removed by the RNA matrix in the Rnaid kit. The sensitivity of RT-PCR and nested PCR with RNA extracted from BCV diluted in maintenance medium or nasal swab suspensions were the same and was not affected by inhibitory substances in the nasal swab suspensions. Therefore, RNA purification with RNA matrix in the kit used in the present study was highly effective to remove nonspecific inhibitors possibly present in the nasal swab suspensions.

In this study, the BRCV 930, CD DB2 and WD DBA strains of BCV infected and caused diarrhea in Cols-D and gnotobiotic calves. By ELISA and RT-PCR, the patterns of fecal and nasal shedding of BCV observed after primary inoculation with either the BRCV 930, CD DB2, or WD DBA strains were similar to those reported in other studies of gnotobiotic, Cols-D, or field calves infected with 
CD or WD BCV strains [7, 10, 18, 19, 21, 26]. To our knowledge, however, there are no published studies of in vivo cross-protection between BRCV and CD or WD BCV strains. In the present study, calves that recovered from infection with BRCV, CD or WD strains of BCV were protected from BCV-associated diarrhea after challenge exposure with either the BRCV, CD or WD strains of $\mathrm{BCV}$. This result was consistent with previous reports in which calves recovered from primary infection with CD DB2 or WD DBA BCV strains were protected from $\mathrm{BCV}$-associated diarrhea after challenge exposure with either the WD DBA or CD DB2 strains of BCV [7].

A high degree of sensitivity is desirable in BCV assays, especially for specimens from calves early or late in the course of illness or after reinfection that may have low levels of BCV shedding. In the present study, the sensitivity and specificity of RT-PCR compared with ELISA were high. Although the sensitivity of nested PCR compared with ELISA was very high, the specificity was low. The correlation between the ELISA and RT-PCR assays with nasal and fecal samples was considered good, 92.5 and $95.1 \%$ agreement and $\kappa=0.66$ and 0.81 , respectively. However, the correlation between the ELISA and nested PCR assays with nasal and fecal samples was considered poor and acceptable, $76.1 \%$ and $71.6 \%$ agreement and $\kappa=0.35$ and 0.37 . These results indicate the sensitivity of RT-PCR and nested PCR was very high.

There is a report that calves that were inoculated with the WD DBA strain and then challenge-exposed to the CD DB2 strain were completely protected from fecal shedding of BCV [7]. However, 2 of 4 calves had a few infected nasal epithelial cells for 2 to 4 days after challenge exposure, suggesting reinfection of the upper respiratory tract by the CD DB2 strain of BCV [7]. Although in the present study calves recovered from primary infection with $\mathrm{BCV}$ were protected from $\mathrm{BCV}$ associated diarrhea after challenge exposure, low amount of nasal and fecal virus shedding of BCV, which were detectable only by nested PCR, were observed in all calves but the homologous virus challenged calf (No. 3) on PID 1-3 for 3-11 days. In addition, low amounts of nasal and fecal virus shedding of BCV was observed in nasal and fecal samples obtained from inoculated calves before or after diarrhea. To confirm whether the early shedding of $\mathrm{BCV}$ was due to BCV RNA derived from the inoculum, a gnotobiotic calf was inoculated with inactivated BRCV 930 strain and the fecal and nasal swab samples obtained were tested by ELISA, RT-PCR and nested PCR. No BCV antigen or RNA was detected in these samples even at 1-2 PID. These results suggest that the present nested PCR assay might be useful for diagnosis of subclinical $\mathrm{BCV}$ infections in calves. However it is unknown if the inoculated and challenged calves shedding BCV RNA by nested PCR only are capable of transmitting BCV infection to susceptible cohorts. This should be examined in future studies. The subclinical nasal and fecal shedding of BRCV, CD and WD BCV RNA detected by nested PCR in experimentally challenge-exposed calves agrees with results of field studies that documented chronic, repeated nasal shedding of BCV by infected calves [10] and chronic fecal shedding of BCV in healthy adult cattle detected by ELISA [14]. 
In the present study, no major differences were observed in IgG antibody titers to BCV in serum of the various experimental calves. This finding is in concordance with the report of El-Kanawati et al. [7], who noted that the IgG antibody titers in serum increased after challenge exposure with heterologous BCV strains. In addition, the IgG antibody titers to BCV in the serum of a calf that was inoculated and challenge-exposed to the same strain, BRCV 930, also increased after challenge exposure.

In the present study, all calves inoculated with BRCV, CD or WD strains of BCV and then challenged 3-4 weeks later with either BRCV, CD or WD strains of $\mathrm{BCV}$ developed diarrhea, then recovered and were protected from $\mathrm{BCV}$-associated diarrhea after challenge exposure with either the homologous or heterologous BCV strains. Nasal and fecal shedding of BCV, which were detectable only by nested PCR, after challenge exposure confirmed field and experimental data documenting reinfection of the respiratory and enteric tracts of cattle, suggesting that, in closed herds, respiratory or enteric tract reinfections may constitute a source of BCV transmission to cows (WD) or young calves. In addition, the present 1-step RT-PCR and nested PCR assays were highly sensitive and specific to detect BCV in nasal swab and fecal specimens. Therefore, these assays might be useful to diagnose BCV infections in calves and adult cows.

\section{References}

1. Chomczynski P, Sacchi N (1987) Single step method of RNA isolation by acid guanidinium thiocyanate-phenol-chloroform extraction. Anal Biochem 162: 156-159

2. Clark MA (1993) Bovine coronavirus. Br Vet J 149: 51-70

3. Compton SR, Rogers DB, Holmes KV, Fertsch D, Remenick J, McGowan JJ (1987) In vitro replication of mouse hepatitis virus strain A59. J Virol 61: 1814-1820

4. Crouch CF, Ohmann HB, Watts TC, Babiuk LA (1985) Chronic shedding of bovine enteric coronavirus antigen-antibody complexes by clinically normal cows. J Gen Virol 66: $1489-1500$

5. Cruciere C, Laporte J (1988) Sequence and analysis of bovine enteric coronavirus (F15) genome. 1. Sequence of the gene coding for the nucleocapsid protein; analysis of the predicted protein. Am Inst Pasteur Virol 139: 123-138

6. De vries AAF, Horzinek MC, Rottier PJM, De Groot RJ (1997) The genome organization of the nidovirales: similarities and differences between arteri-, toro-, and coronaviruses. Sem Virol 8: 33-47

7. El-Kanawati ZR, Tsunemitsu H, Smith DR, Saif LJ (1996) Infection and cross-protection studies of winter dysentery and calf diarrhea bovine coronavirus strains in colostrumdeprived and gnotobiotic calves. Am J Vet Res 57: 48-53

8. Fukutomi T, Tsunemitsu H, Akashi H (1999) Detection of bovine coronaviruses from adult cows with epizootic diarrhea and their antigenic and biological diversities. Arch Virol 144: 997-1006

9. Hasoksuz M, Lathrop SL, Gadfield KL, Saif LJ (1999) Isolation of bovine respiratory coronaviruses from feedlot cattle and comparison of their biological and antigenic properties with bovine enteric coronaviruses. Am J Vet Res 60: 1227-1233

10. Heckert RA, Saif LJ, Myers G, Agnes AG (1991) Epidemiologic factors and isotypespecific antibody responses in serum and mucosal secretions of dairy calves with 
bovine coronavirus respiratory tract and enteric tract infections. Am J Vet Res 52: $845-851$

11. Husain M, Seth P, Broor S (1995) Detection of group A rotavirus by reverse transcriptase and polymerase chain reaction in feces from children with acute gastroenteritis. Arch Virol 140: 1225-1233

12. Lapps W, Hogue BG, Brian DA (1987) Sequence analysis of the bovine coronavirus nucleocapsid and matrix protein genes. Virology 157: 47-57

13. Lathrop SL, Wittum TE, Loerch SC, Saif LJ (2000) Bovine coronavirus respiratory shedding and antibody titers in feedlot cattle. Am J Vet Res

14. Lathrop SL, Wittum TE, Brock KV, Saif LJ (2000) The association between bovine coronavirus respiratory tract infection and health and growth performance of feedlot cattle. Am J Vet Res

15. Lucchelli A, Lance SE, Bartlett PB, Miller GY, Saif LJ (1992) Prevalence of bovine group A rotavirus shedding among dairy calves in Ohio. Am J Vet Res 53: 169-174

16. Martin SW (1985) Analysis and causal interpretation of biologic data. A seroepidemiologic study of respiratory disease. Fourth International Symposium on Veterinary Epidemiology and Economics. Vet Med 57: 46-54

17. Martin SW, Bonnett B (1987) Clinical epidemiology. Can Vet J 28: 318-325

18. Reynolds DJ, Debney TG, Hall GA, Thomas LH, Parsons KR (1985) Studies on the relationship between coronaviruses from the intestinal and respiratory tracts of calves. Arch Virol 85: 71-83

19. Saif LJ (1987) Development of nasal, fecal and serum isotype-specific antibodies in calves challenged with bovine coronavirus or rotavirus. Vet Immunol Immunopathol 17: 425-439

20. Saif LJ (1990) A review of evidence implicating bovine coronavirus in the etiology of winter dysentery cows: an enigma resolved? Cornell Vet 80: 303-311

21. Saif LJ, Redman DR, Moorhead PD, Theil KW (1986) Experimentally induced coronavirus infections in calves: Viral replication in the respiratory and intestinal tracts. Am J Vet Res 47: 1426-1432

22. Silva MR, O'Reilly KL, Lin X, Stine L, Storz J (1999) Sensitivity comparison for detection of respiratory bovine coronaviruses in nasal samples from feedlot cattle by ELISA and isolation with the G clone of HRT-18 cells. J Vet Diagn Invest 11: 15-19

23. Smith DR, Tsunemitsu H, Heckert RA, Saif LJ (1996) Evaluation of two antigen-capture ELISAs using polyclonal or monoclonal antibodies for the detection of bovine coronavirus. J Vet Diagn Invest 8: 99-105

24. Spaan WD, Cavanagh D, Horzinek MC (1988) Coronaviruses: structure and genome expression. J Gen Virol 69: 2939-29522

25. Storz J, Stine L, Liem A, Anderson GA (1996) Coronavirus isolation from nasal swab samples in cattle with signs of respiratory tract disease after shipping. J Am Vet Med Assoc 208: 1452-1455

26. Tsunemitsu H, Yonemichi H, Hirai T, Kudo T, Onoe S, Mori K, Shimizu M (1991) Isolation of bovine coronavirus from feces and nasal swabs of calves with diarrhea. J Vet Med Sci 53: 433-437

27. Tsunemitsu H, Saif LJ (1995) Antigenic and biological comparisons of bovine coronaviruses derived from neonatal calf diarrhea and winter dysentery of adult cattle. Arch Virol 140: 1303-1311

28. Tsunemitsu H, Smith DR, Saif LJ (1999) Experimental inoculation of adult dairy cows with bovine coronavirus and detection of coronavirus in feces by RT-PCR. Arch Virol 144: $167-175$ 
29. Watanabe H, Gust ID, Holmes IH (1978) Human rotavirus and its antibody: their coexistence in feces of infants. J Clin Microbiol 7: 405-409

30. Wilde J, Eiden J, Yolken R (1990) Removal of inhibitory substances from human fecal specimens for detection of group A rotaviruses by reverse transcriptase and polymerase chain reaction. J Clin Microbiol 28: 1300-1307

31. Xu L, Harbour D, McCrae MA (1990) The application of polymerase chain reaction to the detection of rotaviruses in feces. J Virol Methods 27: 29-38

32. Zhang X, Herbst W, Kousoulas KG, Storz J (1994) Comparison of the S genes and the biological properties of respiratory and enteropathogenic bovine coronaviruses. Arch Virol 134: 421-426

Author's address: Dr. L. J. Saif, Food Animal Health Research Program, Department of Veterinary Preventive Medicine, Ohio Agricultural Research and Development Center, The Ohio State University, Wooster, OH 44691, U.S.A.; e-mail: saif.2@osu.edu

Received September 21, 2000 